\title{
TECCIENCIA
}

\section{Implementation of a Series Resonant Inverter to Improve Fluorescent Lamp Efficiency}

\section{Implementación de un Inversor Resonante en Serie para Mejorar la Eficiencia en Lámparas Fluorescentes}

\author{
Jhon Fredy Bayona Navarro ${ }^{1 *}$, Jhon Edwin Vera Vera ${ }^{2}$, Nancy Yaneth Gelvez Garcia ${ }^{3}$ \\ ${ }^{1}$ Universidad Sergio Arboleda, Bogotá, Colombia \\ ${ }^{2}$ Universidad ECCI, Bogotá, Colombia \\ ${ }^{3}$ Universidad Distrital Francisco José de Caldas, Bogotá, Colombia
}

\begin{abstract}
The purpose of this paper is shows some design parameters of a series resonant inverter (SRI) half-bridge configuration applied in lamps, this circuit is novel compared with the inverter resonant in series-parallel circuit (SPRI), in actuality the resonant inverters SPRI are very used to supply the power needed in fluorescent lamps, . In order to analyze the behavior and efficiency, is implemented a circuit SRI to supply the energy needed in a $32 \mathrm{~W}$ fluorescent lamp. The final results show a better efficiency with the proposed circuit compared to a classical SPRI.
\end{abstract}

Keywords: Series Resonant Inverter, Fluorescent lamp, SPRI, SRI.

\section{Resumen}

El propósito de este trabajo es mostrar algunos parámetros de diseño de un inversor resonante serie (ISR) de configuración de medio puente aplicados en las lámparas, este circuito es nuevo en comparación con el inversor resonante en serie-paralelo de circuito (SPRI), en la actualidad los inversores resonantes SPRI son muy utilizadas para suministrar la energía necesaria en las lámparas fluorescentes,. Con el fin de analizar el comportamiento y la eficiencia, se implementa un circuito de SRI para suministrar la energía necesaria en una lámpara fluorescente de $32 \mathrm{~W}$. Los resultados finales muestran una mejor eficiencia con el circuito propuesto en comparación con un SPRI clásica.

Palabras clave: Inversor Resonante Serie, Lámpara Fluorescentes, SPRI, SRI.

\section{Introduction}

In recent years, fluorescent lamps are used in a high percentage, due to the demand of artificial lighting in the world it has been increasing [1] [2] [3] [4].

Bad or imperfect switching is the main cause of power loss in converters; this is due to losses in the switching transition where the voltage and current are nonzero. With increasing switching frequency these transitions occur more often increasing the average power loss in the device. On the other hand the high switching frequencies are desirable, with this parameter filtering components and transformers are reduced, which in turn reduces the size and weight of converters.

Resonant circuits occurs when the voltage switching is zero (ZVS) and the current switching is zero (ZCS), avoiding simultaneous transitions of voltage and current eliminating switching losses, this type of switching is known
*Corresponding Author.

E-mail: jhon.bayona@usa.edu.co
How to cite: Bayona Navarro, J. F., Vera Vera, J. E., Gelvez García, N. Y., Implementation of a Series Resonant Inverter to Improve Fluorescent Lamp Efficiency, TECCIENCIA, Vol. 12 No. 21, 7-12, 2016, DOI: http:/dx.doi.org/ 


\section{TECCIENCIA}

as soft switching [1]. When working with fluorescent lamps as load, the electronic ballasts are implemented with resonant converters in order to achieve ignition voltage and used another converter to achieve its steady state voltage [2] [3] [5]. One of the topologies used for electronic ballasts is the resonant inverter series-parallel (SPRI) which combines different topologies such as class E resonant, half-bridge and full-bridge configuration, within these configurations the most used is the topology SPRI half-bridge due to the reduction of costs in manufacturing [6] [7] [8], Figure 1 shows a typical configuration. This inverter circuit provides the voltage ignition and steady state of the lamp, however during steady state operation, the current through capacitor connected to the electrodes is very high and does not contribute to the power absorbed by the lamp, which means a low efficiency of the ballast.

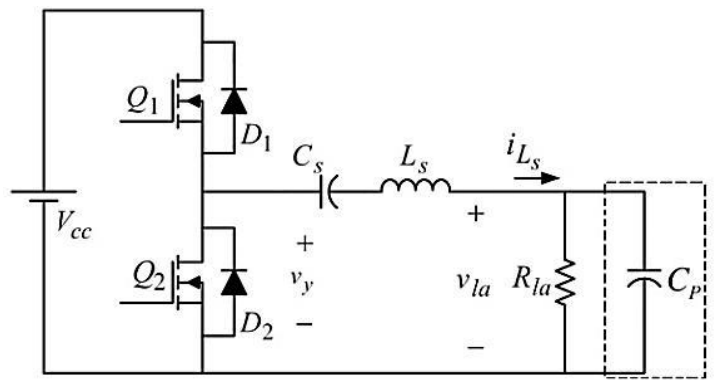

Figure 1 Resonant inverter SPRI.

This work shows in detail a circuit SRI designed to reduce power losses and improve the efficiency of electronic ballast using the first harmonic approximation, additionally some aspects of design are related in order to facilitate its implementation.

\section{Resistance model lamp}

The lamp can be approximated to a resistor that changes with light intensity, for example the RMS voltage of lamp increases almost linearly when the power of the lamp decreases, therefore the lamp behaves as a negative resistance, equally the equivalent resistance of the lamp is in function of its power [9] [10] [11]. Figure 2 shows the equivalent resistance of the lamp decreases as the power increases and increases when the power decreases.

Equations (1) and (2) show a lamp fluorescent model to calculate the equivalent resistive where the parameters $a$ and $b$ can be determined experimentally with the measured data of the lamp [12] [13].

$V_{l a}\left(P_{l a}\right)=a+b P_{l a}$

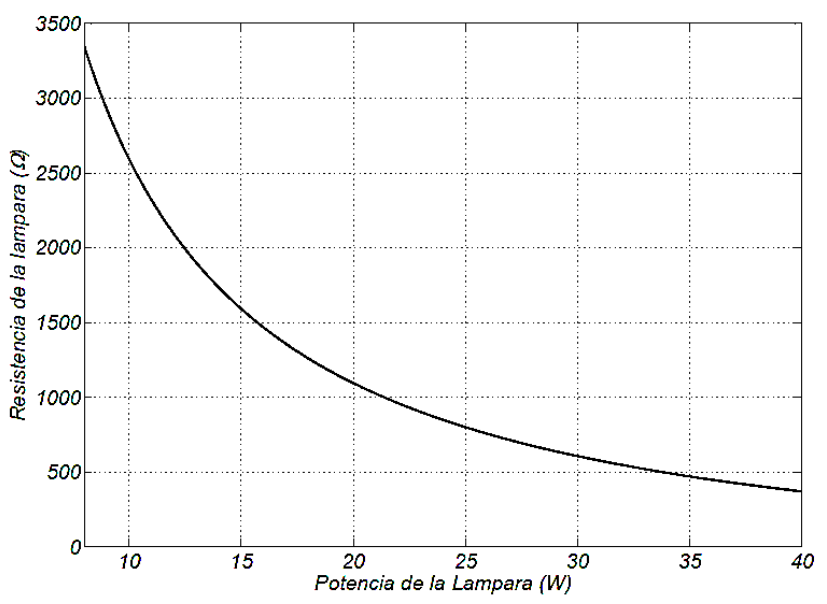

Figure 2 Lamp resistance vs. power.

$$
\begin{aligned}
& R_{l a}\left(P_{l a}\right)=\frac{V_{l a}\left(P_{l a}\right)^{2}}{P_{l a}} \\
& {\left[\begin{array}{l}
a \\
b
\end{array}\right]=\left[\begin{array}{ll}
1 & P_{l a} \text { min } \\
1 & P_{l a} \text { max }
\end{array}\right]-1\left|\begin{array}{l}
V_{l a} \min \\
V_{l a} \text { max }
\end{array}\right|}
\end{aligned}
$$

\section{Inverter resonant series SRI}

In this converter a capacitor and an inductor are connected in series to a load or equivalent resistance of the lamp $R_{l a}$. It is a DC-AC converter in half-bridge configuration, as shown in Figure $3 \mathrm{a}$ the function of this converter is supplying the steady state current of the lamp, $Q 1$ and $Q 2$ are switched alternately ,then a square wave is produced at the midpoint of them. A capacitor $C s$ and an inductance $L s$ are calculated so that the switching frequency equals the resonance frequency.

Figure $3 \mathrm{~b}$ shows a representation a wave at the resonant frequency where the combination LC works as a filter where attenuation of harmonics reflect one sine wave with the same fundamental frequency of the square wave, this can be expressed as the following Fourier series:

$$
v_{y}=\frac{V c c}{2}+\sum_{n=1,3,5, \ldots . .} \frac{2 V c c}{n \pi} \sin \left(n \omega_{s} t\right)
$$

The fundamental component of Eq. (1) is:

$$
v_{y 1}=\frac{2 V c c}{\pi} \sin \left(\omega_{s} t\right) \quad \text { Where } \quad \omega_{s}=2 \pi f_{s}=\frac{2 \pi}{T_{s}}
$$

To analyze the SRI you can use the approximation of first harmonic which has been studied in detail by several authors [5] [6], SRI proposed in this paper operates in continuous 


\section{TECCIENCIA}

conduction mode (CCM) with a high $\mathrm{Q}$ which allows operation SRI through linear AC circuit, as illustrated in Figure 4.
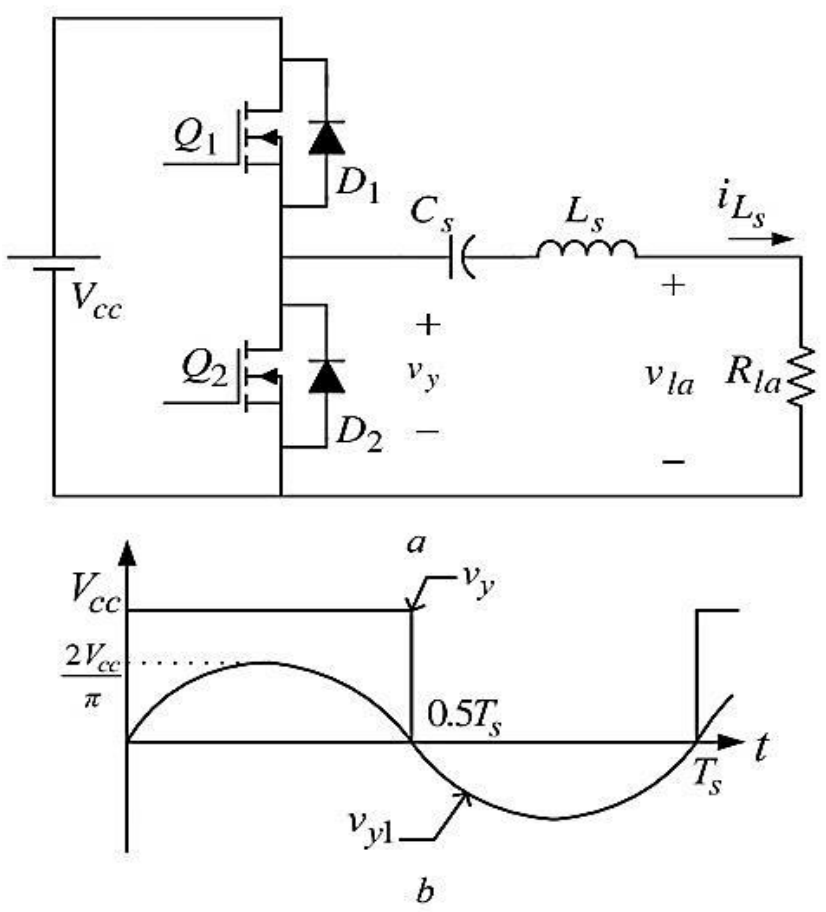

Figure 3 Proposed circuit and switching signal, a) SRI half-bridge., $b$ ) Waveform of $v_{y}$ y $v_{y l}$.

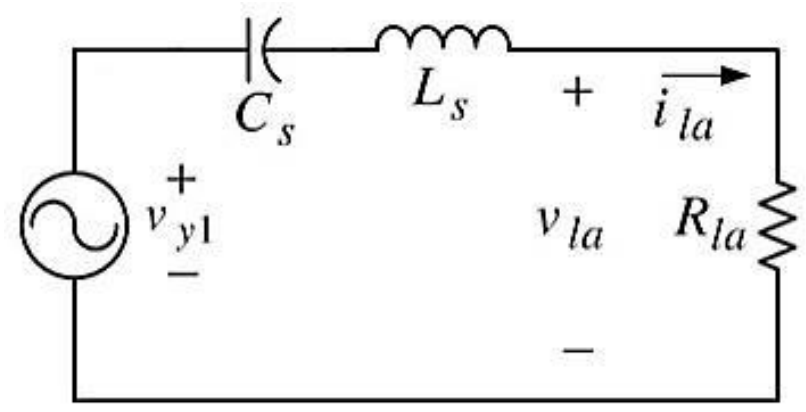

Figure 4 Equivalent circuit AC.

The normalized effective voltage of the lamp depends of $\mathrm{Q}$ on the design chosen and it analyzes considering the reflected values on the Figure 5, this parameter being a determining factor in the design of SRI.

This voltage is defined by the following equation:

$$
V=\frac{V_{l a} r m s}{V_{y 1} r m s}=\frac{1}{\sqrt{\left(\left(F-F^{-1}\right) Q\right)^{2}+1}}
$$

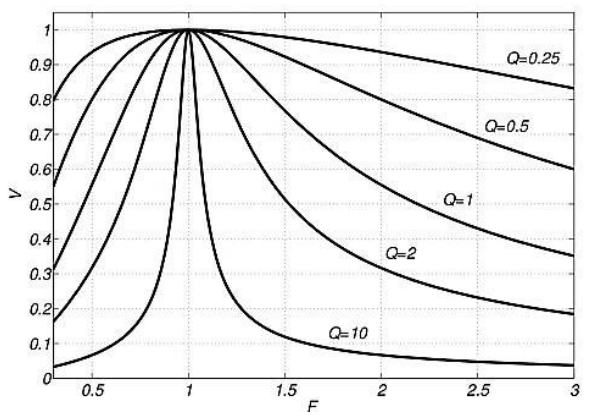

Figure 5 Normalized lamp voltages.

Where the normalized frequency $(\mathrm{F})$ and quality factor $(\mathrm{Q})$ also known as normalized load are given by:

$$
\begin{aligned}
& \boldsymbol{F}=\frac{\omega_{s}}{\omega_{o}}=\omega_{s} \sqrt{L_{s} C_{s}} \\
& Q=\frac{Z_{s}}{R_{l a}}=\sqrt{\frac{L_{s}}{C_{s}}} \frac{1}{R_{l a}}
\end{aligned}
$$

Other parameters that must be present for the design of SRI are:

First, the current LC tank circuit $\left(i_{L}\right)$ which is equal to the current of the lamp $\left(i_{l a}\right)$, and flows through the Mosfet in the SRI, can be obtained considering (3).

Second, the angle $(\alpha)$ that defines the type of switching in Mosfet of SRI is part of the current LC tank circuit and is calculated by the following equation:

$$
\alpha=-\arctan \left(\left(\mathrm{F}-\mathrm{F}^{-1}\right) \mathrm{Q}\right)
$$

As seen in Figures 6 and 7 the angle $(\alpha)$ relates current and voltage to consider in the switching modes.

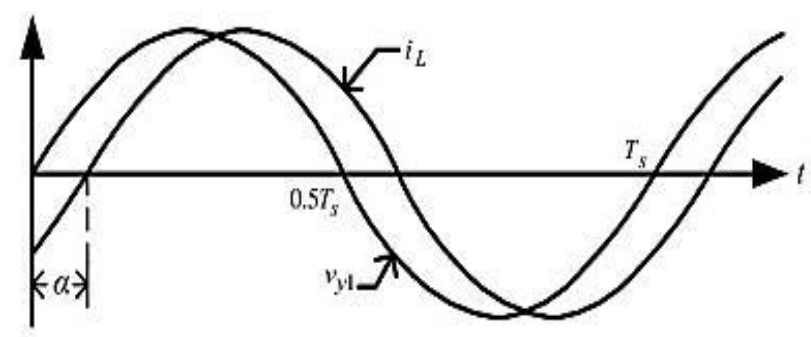

Figure 6 Waveform $v_{y l}$ and $i_{L .}$ 


\section{TECCIENCLA}

\section{Implementation of SRI, SPRI and the ignition circuit}

To provide the ignition voltage of the lamp a converter DC$\mathrm{AC}$ is designed in configuration full-bridge as is shows in Figure 8 is powered by a source $V c c$ and is composed of: Four MOSFETs $Q_{3}, Q_{4}, Q_{5}$ and $Q_{6}$ alternately that ignite for SRI, working the same frequency fs, a transformer $T_{l}$ that providing galvanic isolation and increases the voltage to ignite the lamp and a capacitor $C_{x}$ which removes the DC component produced by the full bridge, to analyze efficiency parameters are measured for SRI and SPRI considering the condenser $C_{p}$ that shows in this circuit.

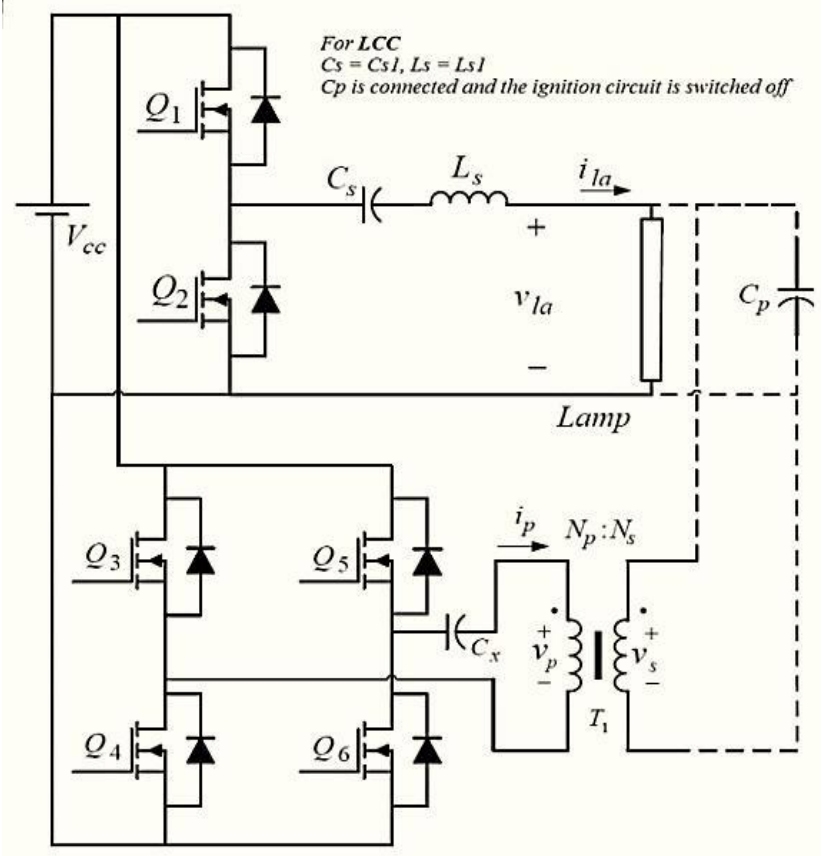

Figure 8 Proposed prototypes.

Experimental measurements of the SRI, SPRI and the ignition circuit were performed using a fluorescent tube of $32 \mathrm{~W}$ brand OSRAM to verify the theoretical analysis. In Figure 9a shown the waveform of the lamp current for a power (Pla) of $32 \mathrm{~W}$, when SRI is used, you can see that waveform is almost sinusoidal, this means that the factor peak is approximately 0.41 , which increases the life the lamp. For a power (Pla) of $28 \mathrm{~W}$ was measured the power of the source Vcc as it is shown in Figure 9b, first using the SRI the power was of $29.6 \mathrm{~W}$, then with SPRI the power was $31.7 \mathrm{~W}$, this means that SRI proposed has a better efficiency compared to traditional SPRI.

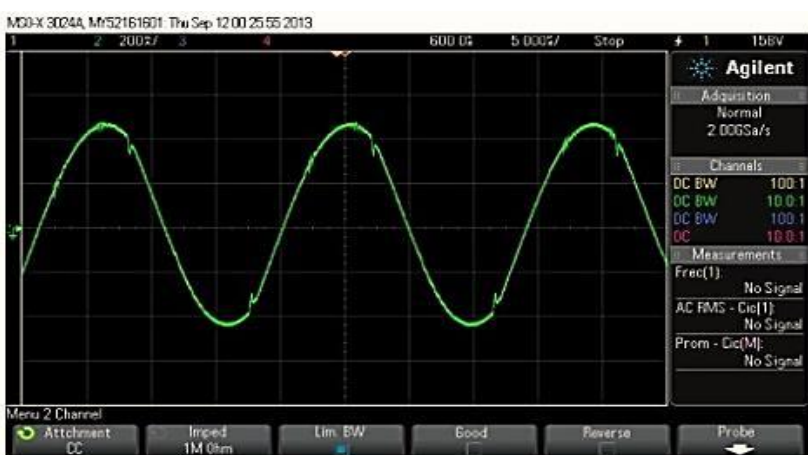

$a$

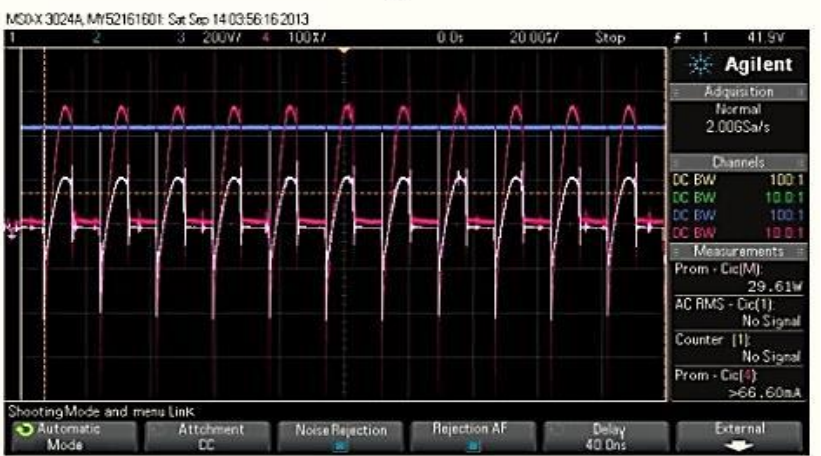

$b$

Figure 9 Waveforms performed in the implemented circuit $a$. Waveform current with SRI

$b$. Power measurement at source $28 \mathrm{~W}$.

\section{Conclusions}

Experimental results developed on a fluorescent lamp $32 \mathrm{~W}$ showed that SRI proposed improved efficiency by $6 \%$ compared to the classic SPRI, this is because the SRI does not use a parallel capacitor to the lamp, reducing losses in the cooper of inductance in the tank circuit LC, the proposed circuit SRI also shows a decrease in the switching or conduction losses on MOSFETs.

\section{References}

[1] T. Liang, C. Cheng, W. Shyu, and J. F. Chen, "Design procedure for resonant components of fluorescent lamps electronic ballast based on lamp model," in Power Electronics and Drive Systems, 2001. Proceedings. 2001 4th IEEE International Conference on, pp, 618-622, vol.2.

[2] J. Chang and G.W. Bruning "Analysis of the self-oscillating series resonant inverter for electronic ballasts" Power Electronics, 1999. IEEE Transactions on, pp, 533-540, Vol 14. 


\section{TECCIENCIA}

[3] F. Tao, "Advanced high-frequency electronic ballasting techniques for gas discharge lamps," Ph.D. dissertation, Virginia Polytechnic Institute and State University, 2009.

[4] Cifuentes, C. and Rodríguez, C. "Sistema de visión global para la plataforma de robot soccer basado en la segmentación de color", TECCIENCIA Vol. 5 No. 10, pp. 7-17, 2011

[5] M. Rashid, POWER ELECTRONICS HANDBOOK. Elsevier Science, 2011

[6] R. W. Erickson and D. Maksimovic, Fundamentals of Power Electronics (Second Edition), 2nd ed. Springer, 2001

[7] D. W. hart, 'Power Electronic', P. Hall, Ed. Pearson Education, 2001 first edition.

[8] A. Maamoun, "An electronic ballast with power factor correction for fluorescent lamps," in Electrical and Computer Engineering, 2000 Canadian Conference on, vol. 1, 2000, pp. 385-389 vol.1.

[9] C. Moo, H. Cheng, T. Lin, and H. Yen, "Designing a dimmable electronic ballast with voltage control for fluorescent lamp," in Industrial Electronics, 1999. ISIE '99. Proceedings of the IEEE International Symposium on, vol. 2, 1999, pp. 786-791 vol.2.

[10] C. Moo, H. Cheng, H. Chen, and H. Yen, "Designing dimmable electronic ballast with frequency control," in Applied Power Electronics Conference and Exposition, 1999. APEC 99. Fourteenth Annual, vol. 2, 1999, pp. 727-733 vol.2

[11] C. Moo, Y. Chuang, Y. Huang, and H. Chen, "Modeling of fluorescent lamps for dimmable electronic ballasts," in Industry Applications Conference, 1996. Thirty-First IAS Annual Meeting, IAS '96, Conference

Record of the 1996 IEEE, vol. 4, 1996, pp. 2231-2236 vol.4.

[12] F. Wakabayashi and C. Canesin, "A high efficiency hpf-zcs-pwm sepic for electronic ballast with multiple tubular fluorescent lamps" in Applied Power Electronics Conference and Exposition, 2012. APEC 2012. Seventeenth Annual IEEE, vol. 2, 2012, pp. 924-930 vol.2.

[13] C. Nascimento, J. Moia, and A. Perin, "A voltage source charge pump power factor correction electronic ballast for fluorescent lamp with no start-up capacitor," in Power Electronics Specialists Conference, 2006. PESC '06. 37th IEEE, 2006, pp. 1-7. 